\title{
Occurrence of Aflatoxin M1 in Raw Milk Marketed in Italy: Exposure Assessment and Risk Characterization
}

\section{OPEN ACCESS}

Edited by:

Victor Ladero,

Spanish National Research Council (CSIC), Spain

Reviewed by:

Carlos Humberto Corassin,

University of São Paulo, Brazil

Elisa Yoko Hirooka,

State University of Londrina, Brazil

Amin Mousavi Khaneghah,

Campinas State University, Brazil

*Correspondence:

Kata Kerekes

kerekes.kata@gmail.com

Specialty section:

This article was submitted to

Food Microbiology,

a section of the journal

Frontiers in Microbiology

Received: 20 May 2019 Accepted: 18 October 2019

Published: 08 November 2019

Citation:

Serraino A, Bonilauri P, Kerekes K, Farkas Z, Giacometti F, Canever A, Zambrini AV and Ambrus Á (2019)

Occurrence of Aflatoxin M1

in Raw Milk Marketed in Italy:

Exposure Assessment and

Risk Characterization.

Front. Microbiol. 10:2516.

doi: 10.3389/fmicb.2019.02516

\begin{abstract}
Andrea Serraino', Paolo Bonilauri', Kata Kerekes ${ }^{3 *}$, Zsuzsa Farkas ${ }^{3}$, Federica Giacometti', Alessandra Canever ${ }^{4}$, Angelo Vittorio Zambrini ${ }^{4}$ and Árpád Ambrus ${ }^{5}$
\end{abstract}

${ }^{1}$ Department of Veterinary Medical Sciences, Alma Mater Studiorum, University of Bologna, Bologna, Italy, ${ }^{2}$ Experimental Zooprophylactic Institute of Lombardy and Emilia-Romagna, Reggio Emilia, Italy, ${ }^{3}$ Department of Food Safety Planning and Monitoring, System Management and Supervision Directorate, National Food Chain Safety Office, Budapest, Hungary, ${ }^{4}$ Department of Quality, Innovation, Safety, Environment, Granarolo S.p.A., Bologna, Italy, ${ }^{5}$ Doctoral School of Nutrition and Food Sciences, University of Debrecen, Debrecen, Hungary

The current study is based on the AFM 1 contamination of milk determined from April 2013 to December 2018 in the framework of a self-control plan of six milk processing plants in Italy. These data - together with the consumption data of milk consumers - were evaluated and used for the calculation of the Estimated Daily Intake (EDI), the Hazard Index $(\mathrm{HI})$, and the fraction of hepatocarcinoma cases $(\mathrm{HCC})$ due to $\mathrm{AFM}_{1}$ exposure in different population groups. Altogether a total of 31,702 milk samples were analyzed, representing 556,413 tons of milk, which is an outstanding amount compared to published studies. The results indicate the monthly fluctuation of $\mathrm{AFM}_{1}$ levels through a period of nearly 6 years. The EDI of $\mathrm{AFM}_{1}$ in different population groups was in the range of 0.025 $0.328 \mathrm{ng} \mathrm{kg}^{-1}$ body weight (bw) per day, based on the average consumption levels and weighted mean contamination of the milk in the study period. Considering average consumptions, in the groups of infants and toddlers, the $\mathrm{HI}$ calculation resulted in 1.64 and 1.4, respectively, while for older age groups, it was $<1$. The estimated fractions of HCC incidences attributable to the AFM 1 intakes were 0.005 and 0.004 cases per 100,000 individuals in the 0-0.9 and 1-2.9-year age groups, respectively, and below 0.004 cases in the other age categories. The monthly average AFM ${ }_{1}$ contamination of tested milk consignments ranged between 7.19 and $22.53 \mathrm{ng} \mathrm{kg}^{-1}$. Although the results of this extensive investigation showed a low risk of $\mathrm{HCC}$, the variability of climatic conditions throughout years that influence $\mathrm{AFB}_{1}$ contamination of feed and consequently $A F M_{1}$ contamination of milk justifies their continuous monitoring and update of the risk assessment.

Keywords: Aflatoxin M1, enzyme-linked immunosorbent assay, cow's milk, raw milk, exposure assessment, food safety risk

\section{INTRODUCTION}

Aflatoxins (AFs) are secondary metabolites produced by Aspergillus flavus, Aspergillus parasiticus, and Aspergillus nominus fungi under certain growing and storage conditions (WHO, 1997; Giorni et al., 2007). The AFs consisted of Aflatoxin $B_{1}, B_{2}, G_{1}$, and $G_{2}$ may contaminate food and feed. Maize grains and other feedstuffs such as corn silage, soybean, and press cakes from 
oil plants can be commonly contaminated by Aspergillus spp. The critical factors facilitating the growth of Aflatoxin-producing molds in corn grains and silage include among others: lack of good agricultural (Kebede et al., 2012), storage practices, and unfavorable climatic conditions (FAO/WHO Codex Alimentarius, 2014; Frazzoli et al., 2017). The risk of Aflatoxin contamination is generally higher in geographical regions with a tropical climate or a subtropical climate (Fakhri et al., 2019a), but an extreme hot and droughty season may promote the growth of Aspergillus spp. in crops and increases their AF contamination as reported in the South and Southwestern regions of Europe (Trevisani et al., 2014; Milićević et al., 2017; Udovicki et al., 2019), the United States (Fakhri et al., 2019a), Turkey (Madali et al., 2018), and in other regions (Rama et al., 2015; Rahmani et al., 2018; Pardakhti and Maleki, 2019). The effects of such conditions on the Aflatoxin contamination of maize prevailed in 2003 and 2012 in the Po valley were evaluated in detail by Canever et al. (2004) and Marchetti et al. (2013).

$\mathrm{AFM}_{1}$ contamination in milk was also reported from a number of countries (EFSA, 2004; Cano-Sancho et al., 2013; Duarte et al., 2013; Tsakiris et al., 2013; Trevisani et al., 2014; Fakhri et al., 2019a,b). In Italy, due to its climatic conditions, the Po valley is considered one of the highest risk areas in this regard, which happens to be the region that produces most of the milk in the country (Frazzoli et al., 2017). Several factors may affect the $\mathrm{AFM}_{1}$ contamination of milk, for example, environmental conditions (Giorni et al., 2007; Prandini et al., 2009; Kebede et al., 2012; Miliĉevic et al., 2019; Fakhri et al., 2019a), different farming and feeding practices, and the quality and safety control system of the food business operators concordant with the different legislations in force.

The mother's milk may also contain $\mathrm{AFM}_{1}$ in comparable concentrations to the dairy cow's milk (Kunter et al., 2017; Radonić et al., 2017; Bogalho et al., 2018; Valitutti et al., 2018; Fakhri et al., 2019a,b).

These conditions justify the increased activity in Italy in the field of basic research (Perrone et al., 2014), biological control (e.g., use of non-aflatoxin-producing strains; Mauro et al., 2014, 2018), monitoring of Aflatoxin levels throughout the milk value chain (Anfossi et al., 2011; Kerekes et al., 2016), development and application of different prevention and intervention procedures (Gallo and Masoero, 2010), analytical methods, and validation protocols for the detection of Aflatoxins (Rosi et al., 2007; Bellio et al., 2016).

\footnotetext{
Abbreviations: AFB1, Aflatoxin B1; 95\% CI, 95\% confidence intervals; $\mathrm{AFM}_{1}$, Aflatoxin M1; AQM, Average quality milk (normal and high quality altogether); $\mathrm{BMDL}_{10}$, Benchmark dose lower confidence limit for a $10 \%$ response; bw, Body weight; EC, European Commission; EDI, Estimated Daily Intake; EFTA, European Free Trade Association; EFSA, European Food Safety Authority; ELISA, Enzymelinked immunosorbent assay; EU, European Union; FAO, Food and Agriculture Organization of the United Nations; HBV, Hepatitis B virus; HCC, Hepatocellular carcinoma; HI, Hazard Index; HPLC, High Performance Liquid Chromatography; HQM, High quality milk; JECFA, Joint FAO/WHO Expert Committee on Food Additives; LCI, Liver cancer incidence; LCL, Lower confidence limit; MoE, Margin of Exposure; NIST, National Institute of Standards and Technology; NQM, Normal quality milk; OM, Organic milk; SD, Standard deviation; TD50, Dose causing $50 \%$ of the animals developing tumor; TDI, Tolerable daily intake; UCL, Upper confidence limit; WHO, World Health Organization; WM, Weighted mean.
}

If ruminants are fed with contaminated feed, the Aflatoxin $\mathrm{B}_{1}$ consumed by the animals is partly degraded by the forestomach before reaching the circulatory system. The remaining part is transformed by the liver into monohydroxy derivative forms: mainly $\mathrm{AFM}_{1}$, and in smaller quantities $\mathrm{AFM}_{2}, \mathrm{AFM}_{4}$, and other metabolites such as aflatoxicol. Afterward, it is being secreted into the milk through the mammary glands (Frazzoli et al., 2017). In dairy cows, the excretion takes $12-24 \mathrm{~h}$ after $\mathrm{AFB}_{1}$ intake, and the depuration interval is about 2-3 days after the animals are fed with $\mathrm{AFB}_{1}$-free feed. The excreted amount of toxin through milk varies between 1 and $6 \%$ of ingested $\mathrm{AFB}_{1}$, depending on the variety of dairy cows and the amount of produced milk. The high-yielding breeds have higher carry-over rate (Tsakiris et al., 2013).

The exposure to Aflatoxins - and other mycotoxins compromises the health of animals and humans as well (Kunter et al., 2017). The International Agency for Research on Cancer (2002) classified $\mathrm{AFB}_{1}$ to Group 1 of carcinogenic substances for humans. Therefore, no tolerable daily intake (TDI ng $\mathrm{AFB}_{1}$ $\mathrm{kg}^{-1}$ bw day ${ }^{-1}$ ) could be set for this substance, and the exposure levels should be kept as low as reasonably achievable. AFM has $2-10 \%$ of the carcinogenic potency of $\mathrm{AFB}_{1}$ but has the same liver toxicity (Hsieh et al., 1984; Cullen et al., 1987).

Milk is a very important food that provides macro- and micronutrients for the growth and development of the body and for the maintenance of human health, but its $\mathrm{AFM}_{1}$ contamination may impose health risk for the consumers. AFM is heat stable and processing, and storage conditions are ineffective in reducing the concentration of $\mathrm{AFM}_{1}$ in milk and milk products (Joint FAO/WHO Expert Committee on Food Additives, 2001; Campagnollo et al., 2016).

The presence of $\mathrm{AFM}_{1}$ in milk and milk products, even in small quantities, represents a concern, mainly because these products are widely consumed by children who are more susceptible to the toxic effects of Aflatoxins, due to their underdeveloped metabolic and immune system (Gonzales-Osnaya et al., 2008; Kunter et al., 2017; Fakhri et al., 2019a).

In view of its hepatotoxicity and potential carcinogenicity, the regulatory agencies established maximum permissible levels

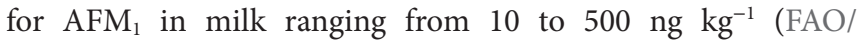
WHO Codex Alimentarius, 1995; European Community, 2006; USA Guidance levels; Bogalho et al., 2018) following the principle of "As low as reasonably achievable" (ALARA), taking into account the inevitable Aflatoxin contamination of feed.

Quantitative exposure assessment is a methodology developed to evaluate the probable intake of chemical substances via food. Aflatoxins are genotoxic and carcinogenic; therefore, there is no intake level, which can be considered risk free (EFSA Scientific Committee, 2007). The safe dose proposed by Kuiper-Goodman (1990) was derived from the dose causing $50 \%$ of the animals developing tumor $\left(\mathrm{TD}_{50}\right)$ divided by a safety factor of 50,000 . The suggested value is $0.2 \mathrm{ng} \mathrm{kg}^{-1}$ of body weight, which was derived from extrapolation to a risk level of 1:100,000. The risk from exposure to genotoxic and carcinogenic substances found in food and feed can be characterized by the margin of exposure (MoE). The MoE provides an indication of the level of safety concern about 
a contaminant's presence in food, but it does not quantify the risk as such. As stated by EFSA Scientific Committee (2012), if it is based on the $\mathrm{BMDL}_{10}$ from an animal study, a margin of exposure of 10,000 or higher (in view of uncertainties) considered being of low concern from a public health point of view. Risk characterization, based on the estimated human exposure and available toxicological reference values, provides important information for risk managers on the probability of occurrence and severity of potential adverse health effects to implement appropriate control measures for assuring the safety of food (Leblanc et al., 2005).

The objectives of this study were to evaluate the annual and monthly fluctuation of $\mathrm{AFM}_{1}$ contamination of milk over a period of 5.5 years, the human exposure, and the potential risk of consumers in different age categories based on the vast amount of $\mathrm{AFM}_{1}$ contamination data in milk representing a significant proportion produced and marketed in Italy during the study period, and use these results to justify the need for continuous monitoring of $\mathrm{AFM}_{1}$ contamination in milk.

\section{MATERIALS AND METHODS}

To provide baseline data for future evaluation of the change in $\mathrm{AFM}_{1}$ contamination, the milk collected in six dairy plants from April 2013 to December 2018 in the framework of a self-control plan of the Italian dairy industry is investigated. The milk processing plants, located in Northern, Central, and Southern Italy, collected about 465 million liters of milk per year. Five of them applied the same self-control plan using $40 \mathrm{ng} \mathrm{\textrm {kg } ^ { - 1 }} \mathrm{AFM}_{1}$ concentration as action limit (AL), while one plant used a $30 \mathrm{ng} \mathrm{kg}^{-1} \mathrm{AL}$. When the $\mathrm{AFM}_{1}$ concentration of the sample reached the AL, the dairy farms were informed, and corrective measures were applied on the farm level in order to avoid high contamination of the milk. The milk was collected from about 650 dairy farms. The routing of the trucks covering diverse number of dairy farms - depending on the amount of milk produced by each farm - was decided on the basis of logistic optimization. Three types of milk were collected: (1) high quality milk (HQM); (2) normal quality milk (NQM); and (3) organic milk (OM). In case of the truck collected milk from different farms, the milk of the same type was mixed, but the three types of milk (HQM, NQM, and $\mathrm{OM}$ ) were loaded in different compartments of the truck.

\section{Description of the Self-Control Plan}

The self-control plan applied for the control of $\mathrm{AFM}_{1}$ content starts with sampling of the milk of the truck before unloading its content. If trucks contained different types of milk, the personnel of the milk processing plants collected one sample from each type of milk during the discharge of the tanker. All samples were analyzed immediately by a rapid commercial immunochromatographic test (Charm MRLAFMQ ${ }^{\circledR}$ Charm Science INC, Lawrence, MA, USA) utilizing highly specific reactions between antibodies and $\mathrm{AFM}_{1}$. It detects $\mathrm{AFM}_{1}$ at or above $25 \mathrm{ng} \mathrm{kg}^{-1}$ in milk and suitable to indicate the

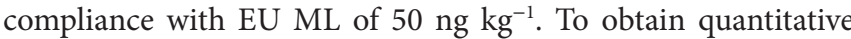
data for the $\mathrm{AFM}_{1}$ as part of a separate program, different milk batches of each collecting zone were also sampled and analyzed at least twice a month with an ELISA kit (Immunoscreen $\mathrm{AFM}_{1}$, Tecna s.r.l., Trieste, Italy), which was validated within the range of 2.5-100 $\mathrm{ng} \mathrm{L}^{-1}$ giving linear response up to $80 \mathrm{ng} \mathrm{L}^{-1}$ (Rosi et al., 2007). Note that the $\mathrm{AFM}_{1}$ contamination was reported in some cases from $1 \mathrm{ng} \mathrm{kg} \mathrm{kg}^{-1}$, which is the limit of detection of the ELISA method applied. The ISO (1998) HPLC-FD reference method (LOQ: $8 \mathrm{ng} \mathrm{L}^{-1}$, linearity 3-1,000 ng $\mathrm{L}^{-1}$ ) was used for confirmation of values higher than $50 \mathrm{ng} \mathrm{kg}^{-1}$. The procedures were performed by the dairy plants as described by Rosi et al. (2007). The performance characteristics of the methods were regularly tested by the plants and periodically verified by the official inspectors according to the HACCP plan of the industries. No further validations of the methods were carried out.

After confirmation that the $\mathrm{AFM}_{1}$ concentration exceeded the legal limit, the competent authority was informed in accordance with the Italian law (Ministero della Salute, 2013). The plants did not process milk with $\mathrm{AFM}_{1}$ content higher

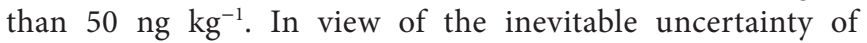
detection with CHARM test and the biweekly frequency of analyses with ELISA tests for obtaining the possible most realistic information on the exposure levels, the $\mathrm{AFM}_{1}$ content

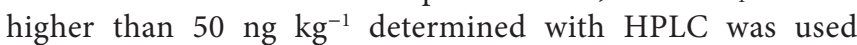
to complement the database obtained with ELISA tests, which did not cover all milk consignments. Data of $\mathrm{AFM}_{1}$ concentration together with the quantity of milk unloaded from each truck were used to calculate the weighted mean $\mathrm{AFM}_{1}$.

\section{Characterization of Data and Exposure Estimation}

Descriptive statistical parameters of the $\mathrm{AFM}_{1}$ concentrations [mean, weighted mean (weight was assigned according to the quantity of milk loaded from the sampled trucks), standard deviation, median, percentile values, and their confidence intervals] were calculated for HQM, NQM, and OM. The percentile values were calculated with NIST method (NIST/ SEMATECH, 2013). The confidence intervals of the mean and percentile values of the three types of milk were overlapping; hence, there was no significant difference between them.

\section{Dietary Exposure Assessment and Risk Characterization}

Food consumption data were obtained from the Comprehensive Food Consumption Database of EFSA ${ }^{1}$. The database contained data derived from the Italian National Food Consumption Survey (INRAN-SCAI) conducted from October 2005 to December 2006. It involved 3,322 consumers from 1,329 households located in the four main geographical areas of Italy (North-West, North-East, Centre and South, and Islands;

${ }^{1}$ EFSA, The Comprehensive Food Consumption Database (2018). https://www. efsa.europa.eu/en/food-consumption/comprehensive-database 
Leclercq et al., 2009). The exposure assessment is based on the mean and 95th percentile "Cattle milk" consumption data of "consumers only" of each population groups: infants (0-0.9 years), toddlers ( $1-2.9$ years), other children (3-9.9 years), adolescents (10-17.9 years), adults (18-64.9 years), elderly $(65-74.9)$, and very elderly ( $>75)$. The proportion of milk consumers of the respective population groups is presented in Table 1.

Data used for EDI calculation are summarized in Table $\mathbf{1 .}$ Since the number of consumers (5) in the infant category was low, these consumption data were substituted by the cattle milk consumption of all available (infant) consumers in the EFSA database in order to provide an approximate estimate for the mean consumption values for the Italian population. The 95th percentile exposure calculations were carried out only on a monthly basis because it is not realistic that such high quantity of milk is consumed over the year.

The estimated daily intakes (EDI: ng $\mathrm{kg}^{-1}$ bw day ${ }^{-1}$ ) of the population groups were calculated as:

$$
\mathrm{EDI}=\frac{\sum\left[\mathrm{WM}_{\mathrm{AFM} 1} \text { concentration }\left(\frac{\mathrm{ng}}{\mathrm{kg}}\right) \times \mathrm{AC}\left(\frac{\mathrm{kg}}{\mathrm{day}}\right)\right]}{[\text { Mean body weight }(\mathrm{kg})]} .
$$

Monthly, yearly, and four-year average EDI values were calculated from the corresponding weighted mean (WM) $\mathrm{AFM}_{1}$ concentrations unloaded from the tankers in the given period of time and the average (AC) and large portion size (95th percentile - as worstcase scenario calculation) consumption data (kg/day).

In order to calculate hazard indices (HI), the monthly, yearly, and four-year average estimated daily intakes were divided with 0.2 (Kuiper-Goodman, 1990). The same approach was also used in other studies (Shundo et al., 2009; Duarte et al., 2013; Tsakiris et al., 2013; Kerekes et al., 2016).

Because $\mathrm{BMDL}_{10}$ value is not available for $\mathrm{AFM}_{1}$, the $\mathrm{BMDL}_{10}$ of $\mathrm{AFB}_{1}\left(870 \mathrm{ng} \mathrm{kg}{ }^{-1}\right.$ bw day ${ }^{-1}$ ) was used as a conservative value. $\mathrm{MoE}$ was calculated by dividing the benchmark dose for a $10 \%$ increase in hepatocellular carcinoma (HCC) incidence $\left(\mathrm{BMDL}_{10}\right)$ by the human exposure (EDI) values. The $\mathrm{MoE}$ then was divided by the mean or 95th percentile EDI values for each population groups. The calculation was carried out for each month from April 2013 to December 2018.

The prevalence of carriers of hepatitis B (HBV) in the Italian population is between 1.2 and 2\% (Serraino et al., 2003). The risk potency was calculated assuming that $2 \%$ of population is $\mathrm{HBV}+$ and using the cancer potencies for $\mathrm{AFB}_{1}$, which was estimated by JECFA to be 0.01 for hepatitis $B$ surface antigen negative (HBsAg-) individuals and 0.3 for $\mathrm{HBsAg}+$ individuals (JECFA, 1998). Based on the given cancer potencies, the risk potency can be calculated as follows $=0.01 \times 98 \%+0.3 \times 2 \%=$ $0.016 \mathrm{HCC} /$ year per 100,000 persons (Cano-Sancho et al., 2013). The proportion of population at risk was estimated by multiplying the risk potency with the $\mathrm{BMDL}_{10}$ and then dividing with the MoE considering the mean and 95th percentile of exposure estimation:

$$
\text { Population at risk }=\frac{\text { risk potency } \times \mathrm{BMDL}_{10}}{\mathrm{MoE}}
$$

\section{RESULTS}

\section{Aflatoxin M1 Results}

A total of 31,702 milk samples were analyzed for $\mathrm{AFM}_{1}$, representing 556,413 tons of milk, which comprised 16,107 $(304,625,633 \mathrm{~kg}), \quad 13,726 \quad(222,189,472 \mathrm{~kg})$, and 1,869 $(29,598,042 \mathrm{~kg})$ trucks (batches) of HQM, NQM, and OM, respectively, during 2013-2018.

As the confidence intervals of the median values of the $\mathrm{AFM}_{1}$ contamination in HQM and NQM overlapped, these data were merged into one subset (AQM - average quality milk). The difference between the Northern, Central, and Southern regions was negligible, however, the median values of AQM were statistically different from that of organic milk $\left(\mathrm{OM} 8 \mathrm{ng} \mathrm{kg}^{-1}\right.$ ) collected only in the Northern region. Details of the descriptive statistics of the $\mathrm{AFM}_{1}$ levels for AQM and $\mathrm{OM}$ are reported in Table 2 . The differences between the number of samples taken in each region should be noted. Figure 1 demonstrates the changes occurring throughout the years. In 2017 and 2018, the levels of contamination were

\begin{tabular}{|c|c|c|c|c|c|}
\hline Population Group & Number of consumers & $\begin{array}{l}\text { Percentage of milk } \\
\text { consumers }{ }^{1}\end{array}$ & $\begin{array}{l}\text { Mean consumption } \\
\left(\text { (g day }^{-1}\right)\end{array}$ & $\begin{array}{l}\text { 95th percentile } \\
\text { consumption }\left(\mathrm{g} \mathrm{day}^{-1}\right)\end{array}$ & Mean body weight (kg) \\
\hline Infants & $2,396^{2}$ & $36.61 \%$ & $131.52^{2}$ & $348.13^{2}$ & 5.00 \\
\hline Toddlers & $33^{3}$ & $91.67 \%$ & $269.01^{3}$ & $600.00^{3}$ & 12.00 \\
\hline Other children & 184 & $95.34 \%$ & 205.98 & 392.50 & 26.10 \\
\hline Adolescents & 208 & $84.21 \%$ & 177.80 & 305.42 & 52.60 \\
\hline Adults & 1,733 & $74.92 \%$ & 136.03 & 275.88 & 70.00 \\
\hline Elderly & 223 & $76.90 \%$ & 141.10 & 266.25 & 70.10 \\
\hline Very elderly & 188 & $82.46 \%$ & 177.13 & 337.19 & 70.10 \\
\hline
\end{tabular}

TABLE 1 | Mean body weight and cow milk consumption data used for Estimated Daily Intake (EDI) calculation in different age groups.

${ }^{1}$ Percentage of population groups consuming milk in Italy. EFSA, The Comprehensive Food Consumption Database (2018).

${ }^{2}$ Because the number of consumption data was low (5), the original data were substituted by the calculated European averages: 132 and $348 \mathrm{~g}$ day ${ }^{-1}$.

${ }^{3}$ Although the number of consumption data was also low in this category, the data were not substituted, because they were the same as the European averages: 270 and $600 \mathrm{~g} \mathrm{day}^{-1}$. 
TABLE 2 | Distribution of Aflatoxin $\mathrm{M}_{1}$ concentration $\left(\mathrm{ng} \mathrm{kg}^{-1}\right)$ in different milk types and in various geographical areas of Italy during the 5.5 -year period.

\begin{tabular}{|c|c|c|c|c|c|c|c|c|c|c|c|c|}
\hline \multirow{4}{*}{$\begin{array}{l}\text { Number of } \\
\text { samples } \\
\text { Confidence } \\
\text { intervals } \\
\text { Mean } \\
\text { concentration }\end{array}$} & \multicolumn{3}{|c|}{$\mathrm{OM}^{1}{ }^{1}$ Northern Italy } & \multicolumn{3}{|c|}{$\mathrm{AQM}^{2}$ Northern Italy } & \multicolumn{3}{|c|}{$\mathrm{AQM}^{2}$ Central Italy } & \multicolumn{3}{|c|}{$\mathrm{AQM}^{2}$ Southern Italy } \\
\hline & \multicolumn{3}{|c|}{1,869} & \multicolumn{3}{|c|}{20,574} & \multicolumn{3}{|c|}{2,438} & \multicolumn{3}{|c|}{6,821} \\
\hline & \multirow{2}{*}{$\begin{array}{c}\mathbf{9 5 \%} \mathbf{C l} \\
10.3\end{array}$} & \multicolumn{2}{|c|}{ (LCL-UCL) } & \multirow{2}{*}{$\begin{array}{c}95 \% \text { Cl } \\
12.6\end{array}$} & \multicolumn{2}{|c|}{ (LCL-UCL) } & \multirow{2}{*}{$\begin{array}{c}\mathbf{9 5 \%} \mathbf{C l} \\
13.3\end{array}$} & \multicolumn{2}{|c|}{ (LCL-UCL) } & \multirow{2}{*}{$\begin{array}{c}95 \% \text { Cl } \\
11.4\end{array}$} & \multicolumn{2}{|c|}{ (LCL-UCL) } \\
\hline & & 9.9 & 10.6 & & 12.5 & 12.7 & & 12.9 & 13.6 & & 11.3 & 11.6 \\
\hline $\mathrm{SD}$ & 7.7 & & & 8.5 & & & 8.6 & & & 7.5 & & \\
\hline Median & 8 & 8 & 9 & 10 & 10 & 11 & 11 & 11 & 11 & 9 & 9 & 10 \\
\hline P0.90 & 18 & 17 & 20 & 23 & 23 & 23 & 24 & 24 & 26 & 21 & 20 & 21 \\
\hline P0.95 & 24 & 23 & 27 & 28 & 28 & 29 & 30 & 29 & 33 & 26 & 25 & 27 \\
\hline P0.975 & 30 & 29 & 33 & 34 & 34 & 35 & 38 & 35 & 40 & 32 & 30 & 33 \\
\hline P0.99 & 41 & 36 & 49 & 41 & 40 & 41 & 43 & 41 & 46 & 40 & 38 & 40 \\
\hline $\begin{array}{l}\text { Weighted mean } \\
\text { concentration }\end{array}$ & 10.8 & 10.4 & 11.1 & 12.6 & 12.5 & 12.6 & 13.4 & 13.0 & 13.7 & 11.7 & 11.6 & 11.9 \\
\hline
\end{tabular}

The percentile values (P0.90-P0.99) were calculated with the NIST method; LCL and UCL are the lower and upper 95\% confidence intervals (Cl). ${ }^{1}$ Organic milk. ${ }^{2}$ Average quality milk.

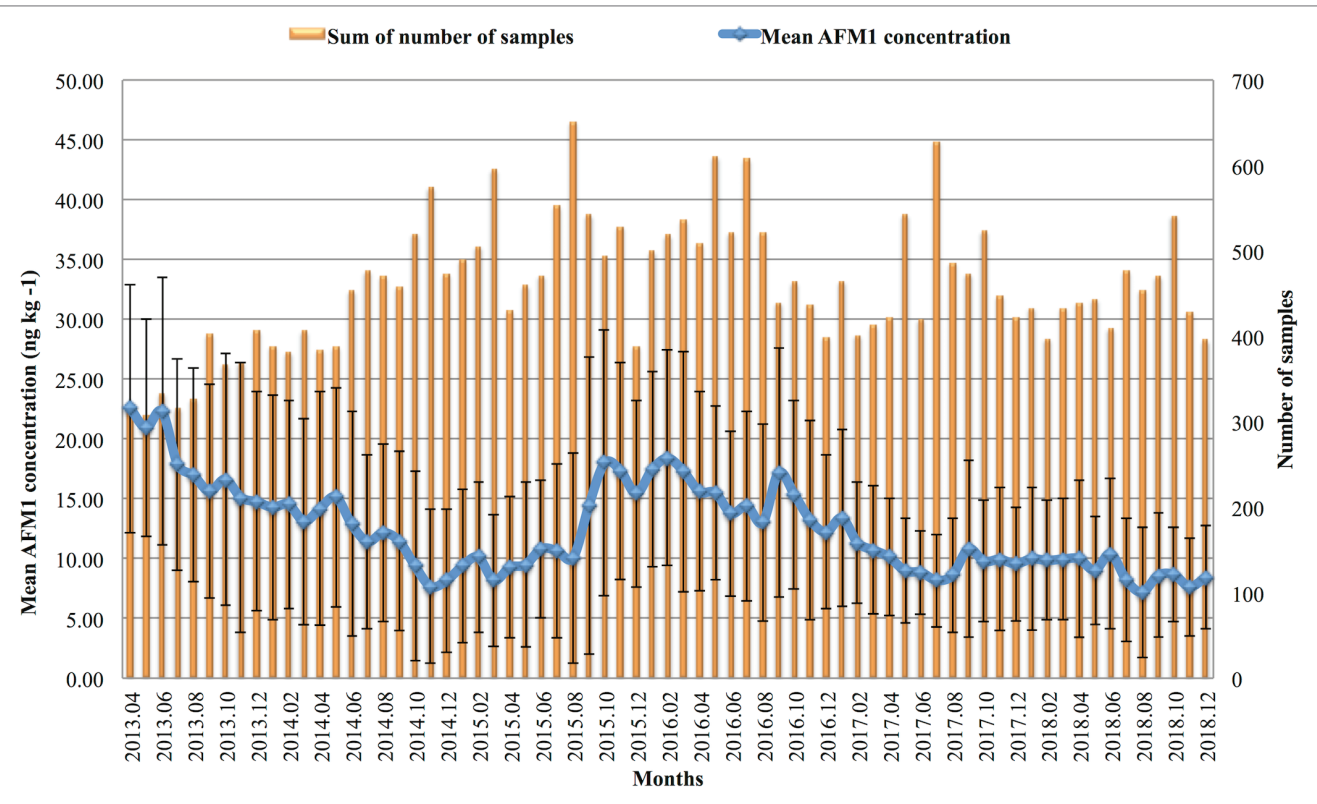

FIGURE 1 | Monthly summary of the total number of samples analyzed and the mean Aflatoxin $M_{1}\left(A_{F} M_{1}\right)$ concentration and standard deviation of milk samples in the given month.

about the same as it was observed from December 2014 through August 2015. However, between September 2015 and December 2016, the $\mathrm{AFM}_{1}$ contamination was nearly as high as in 2013 during the Aflatoxin crisis.

\section{Exposure Assessment}

The monthly and yearly averages of EDI, HI, and liver cancer incidence (LCI) values were calculated together with their average values for the whole study period. In Figure 2, the results of monthly EDI calculations, based on mean and large portion size consumption (95th percentile) data, are shown for two different age categories: toddlers and the adult population. Among adults, the mean EDI values varied between 0.02 and $0.08 \mathrm{ng} \mathrm{kg}^{-1}$ bw day ${ }^{-1}$ during the study period, and for the large portion size consumers, the results were between 0.04 and $0.13 \mathrm{ng} \mathrm{kg}^{-1} \mathrm{bw} \mathrm{day}{ }^{-1}$. In the population of infants, mean EDI of $\mathrm{AFM}_{1}$ resulted in the monthly range of $0.19-0.61 \mathrm{ng} \mathrm{kg}^{-1}$ bw $\mathrm{day}^{-1}$, and in the range of $0.49-1.62 \mathrm{ng} \mathrm{kg}^{-1}$ bw $\mathrm{day}^{-1}$ considering the 95th percentile consumption values. Similarly, among toddlers, the mean EDI values varied between 0.16 and $0.52 \mathrm{ng} \mathrm{kg}^{-1}$ bw day $^{-1}$. In case of large portion size consumers, the results ranged between 0.35 and $1.16 \mathrm{ng} \mathrm{kg}^{-1}$ bw day ${ }^{-1}$. Naturally, the EDI patterns throughout the years follow the same pattern as the weighted mean $\mathrm{AFM}_{1}$ concentrations presented in Figure 1. 
To facilitate the interpretation of EDI values, the corresponding hazard indices (HIs) were calculated by dividing the (monthly, yearly, or four-year average) EDI with 0.2 (the "safe dose"). The calculation shows the amount of $\mathrm{AFM}_{1}$ of concern (HI value $>1$ ). The results of yearly mean hazard index calculations for each population groups are presented in Figure 3.
Over the age of 3 years, the HI was $<1$ considering mean intake values. However, for infants and toddlers, the observed intake levels resulted in HI values higher than 1 in each year during the study period.

The fraction of incidence of HCC or liver cancer incidence (LCI) attributable to the intake of $\mathrm{AFM}_{1}$ was taken into account on the basis of MoE considering the estimated mean exposure.
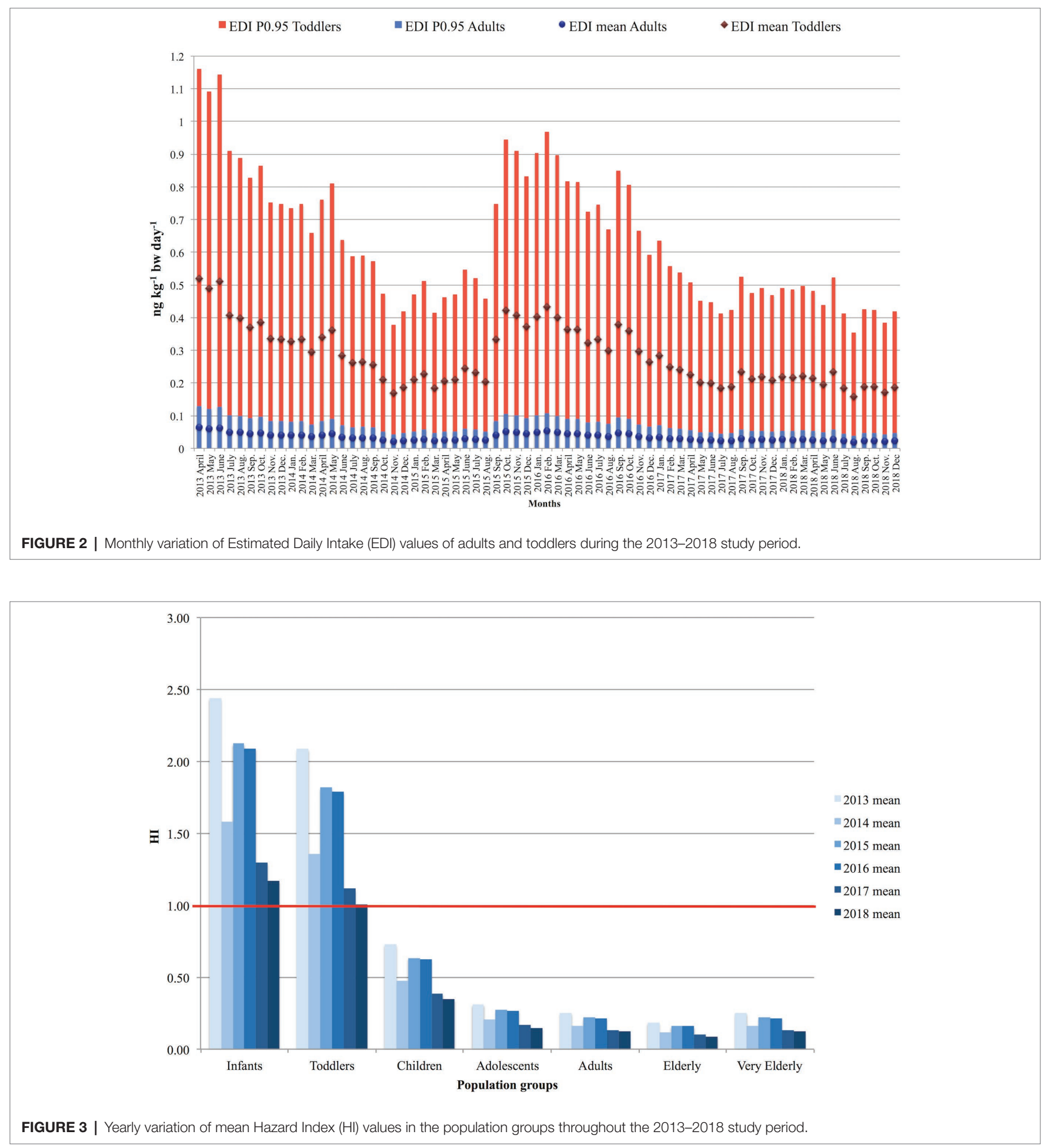
TABLE 3 | "Heat map" (scale: green-yellow-red) of the estimated yearly average liver cancer incidence (LCI) (cases per 100,000 people) in the Italian population by age groups during 2013-2018.

\begin{tabular}{|c|c|c|c|c|c|c|c|}
\hline Year/Age group & Infants & Toddlers & Children & Adolescents & Adults & Elderly & Very Elderly \\
\hline 2013 & 0.0078 & 0.0067 & 0.0023 & 0.0010 & 0.0008 & 0.0006 & 0.0008 \\
\hline 2014 & 0.0051 & 0.0043 & 0.0015 & 0.0006 & 0.0005 & 0.0004 & 0.0005 \\
\hline 2015 & 0.0068 & 0.0058 & 0.0020 & 0.0009 & 0.0007 & 0.0005 & 0.0007 \\
\hline 2016 & 0.0067 & 0.0057 & 0.0020 & 0.0009 & 0.0007 & 0.0005 & 0.0007 \\
\hline 2017 & 0.0042 & 0.0036 & 0.0012 & 0.0005 & 0.0004 & 0.0003 & 0.0004 \\
\hline 2018 & 0.0038 & 0.0032 & 0.0011 & 0.0005 & 0.0004 & 0.0003 & 0.0004 \\
\hline
\end{tabular}

The yearly average LCI values for the whole study period are reported for the population groups in Table 3. The calculation predicted a low additional number of cases in the examined age categories.

Based on the mean consumption and yearly weighted mean $\mathrm{AFM}_{1}$ concentration, the HCC incidence cases were between 0.0004 and $0.0008,0.0032$ and 0.0067 , and 0.0038 and 0.0078 per 100,000 people for adults, toddlers, and infants, respectively. The highest risk group is the infants.

\section{DISCUSSION}

The reported concentration of $\mathrm{AFM}_{1}$ in milk varied widely in recent years worldwide, ranging from non-detects to values up to $48,000 \mathrm{ng} \mathrm{kg}^{-1}$ (Shundo et al., 2009; Duarte et al., 2013; Tsakiris et al., 2013; Oluwafemi et al., 2014; Scaglioni et al., 2014; Temamogullari and Kanici, 2014; Flores-Flores et al., 2015; Rahmani et al., 2018; Fakhri et al., 2019a).

In our study, $63(0.20 \%)$ raw milk samples collected from trucks contained $\mathrm{AFM}_{1}$ higher than $50 \mathrm{ng} \mathrm{kg}^{-1}$. These batches were discarded. The raw milk complying with EC regulation was processed to pasteurize and UHT milk as well as for cheese and other milk-based products. The mean $\mathrm{AFM}_{1}$ concentrations were between $10.3 \mathrm{ng} \mathrm{kg} \mathrm{kg}^{-1}$ in $\mathrm{OM}$ and $12.4 \mathrm{ng} \mathrm{kg}^{-1}$ in AQM with a weighted mean of 10.9 and $12.5 \mathrm{ng} \mathrm{kg}^{-1}$, respectively. These data are comparable with the mean contamination levels previously reported in other European countries such as Spain $\left(n=603\right.$, mean $=9.69 \mathrm{ng} \mathrm{L}^{-1}$ in UHT milk; Cano-Sancho et al., 2013), France $(n=264$, mean $=14.3 \mathrm{ng} \mathrm{kg}^{-1}$ in raw milk; Boudra et al., 2007), and Portugal $\left(n=40\right.$, mean $=23.4 \mathrm{ng} \mathrm{\textrm {L } ^ { - 1 }}$ in pasteurized milk; Duarte et al., 2013) except in Serbia (ranging from 5 to $1,260 \mathrm{ng} \mathrm{kg}{ }^{-1}$; mean $71 \pm 130$; Milićević et al., 2017). The percentages of non-compliant samples were in the lower range of the results ( 0 and $9.1 \%$ in raw milk) reported in previous studies (Roussi et al., 2002; Rodríguez-Velasco et al., 2003; Martins et al., 2005; Boudra et al., 2007; Milićević et al., 2017).

Comparison of the results reported in this study (2013-2018) with data obtained during the mycotoxin crisis (1999-2004) by the same industry shows a clear reduction in $\mathrm{AFM}_{1}$ concentration. Both the percentage of milk batches containing $\mathrm{AFM}_{1}$ above the EU limit and the mean $\mathrm{AFM}_{1}$ concentration decreased (see Table 4). The investigations performed during 2005-2010 showed a higher percentage of non-compliant batches than the present investigation. The notable reduction of the ratio of samples over the legal limit is attributed to the regular monitoring of raw milk, and timely advice is given to the dairy farms for corrective measures.

In view of the similar mean $\mathrm{AFM}_{1}$ concentrations and the lack of data on the different consumption levels of HQM, NQM, or OM among the Italian population groups, the exposure assessment was performed using the combined database of all types of milk and the average daily milk consumption.

The EDI and HI results indicate that - due to the relatively large milk intake compared to their body weights - infants and toddlers are the two most exposed groups of the population to $\mathrm{AFM}_{1}$. As demonstrated in Figure 2, the EDI of the other population groups (adolescents-adults-elderly-very elderly) resulted in a significantly lower range of $0.01-0.18 \mathrm{ng} \mathrm{kg}^{-1}$ bw $\mathrm{day}^{-1}$, while infants and toddlers are exposed to $0.35-1.16 \mathrm{ng} \mathrm{kg}^{-1}$ bw day $^{-1}$ daily intake levels. The latter data are in line with previously reported mean EDIs of $0.08 \mathrm{ng} \mathrm{kg}^{-1}$ bw day ${ }^{-1}(n=40)$ in Portugal (Duarte et al., 2013), $0.09 \mathrm{ng} \mathrm{kg}^{-1} \mathrm{bw} \mathrm{day}^{-1}(n=16)$ in France (Leblanc et al., 2005), and 0.18-0.20 $\mathrm{ng} \mathrm{kg}^{-1}$ bw day $^{-1}(n=1,233)$ in Serbia (Milićević et al., 2017). The calculated monthly and yearly mean $\mathrm{HI}$ values were $<1$ in the age groups of adolescents, adults, elderly, and very elderly, but for infants, toddlers, and children, the results are close to or well over 1, which means that the amount of $\mathrm{AFM}_{1}$ consumed with milk (Figure 3) might be a considerable risk. The higher HI values for younger consumers compared to older age groups are in agreement with the results of Tsakiris et al. (2013); however, the results of this study show a higher exposure level. The slight differences in the outcome of the two studies can be explained by the different calculation methods - considering "consumers only" in this study - and the number of samples.

The LCI estimated in other population groups is significantly lower (Table 3). The estimated fraction of incidence of HCC in the Italian population that predicted a slight increase in cases due to milk consumption is in line with those reported previously by Trevisani et al. (2006; 0.011-0.057 cases/100,000 people in different age categories).

The results of the current study represent the exposure of people consuming milk. Therefore, the estimates cannot be extrapolated to the whole age groups including non-consumers.

Comparison of our results with the previously reported ones should be made with caution, because the latter ones are based on much fewer samples taken within a short period of time compared to our database. Even the comprehensive review on the presence of mycotoxins in animal milk (Flores-Flores et al., 2015) covering 38 countries during the period of 1991-2012 
TABLE 4 | AFM 1 concentration and the ratio of non-compliant samples of raw milk collected in Italy by the same milk processing plants during a 17-year period.

\begin{tabular}{|c|c|c|c|c|c|}
\hline Year(s) & Number of samples & $\begin{array}{c}\text { Mean AFM } \\
\text { concentration }\left(\mathrm{ng} \mathrm{kg}^{-1}\right)\end{array}$ & 95th percentile & $\begin{array}{c}\text { Number of samples } \\
>50 \text { ppt }(\%)\end{array}$ & Reference \\
\hline 2000-2001 & 791 & $27-30^{* *}$ & $\mathrm{NA}^{*}$ & 23.5 & Serraino et al. (2003) \\
\hline Jan. 2001-July 2004 & 2,512 & 29-34 & 80 & $\mathrm{NA}^{*}$ & Trevisani et al. (2006) \\
\hline Sep. 2003-July 2004 & 4,190 & 35 & 80 & $\mathrm{NA}^{*}$ & Trevisani et al. (2006) \\
\hline 2005 & 4,886 & $12-19^{* *}$ & $30-40 *$ & $0.7-3.1^{* *}$ & Trevisani et al. (2014) \\
\hline 2006 & 4,718 & $13-15^{* *}$ & $33-40 *$ & $0.6-1.7^{* *}$ & Trevisani et al. (2014) \\
\hline 2007 & 4,354 & $11-13^{* *}$ & $27-29^{* *}$ & $0.3-1.1^{\text {** }}$ & Trevisani et al. (2014) \\
\hline 2008 & 4,195 & $15-18^{* *}$ & $30-38 * *$ & $1.7-2.5^{\star *}$ & Trevisani et al. (2014) \\
\hline 2010 & 3,740 & $11-12^{* *}$ & $25-28^{* *}$ & $0.5-0.7^{+*}$ & Trevisani et al. (2014) \\
\hline 2013-2014 & 9,017 & $13-17^{* *}$ & $29-35^{* *}$ & 0.24 & Kerekes et al. (2016) \\
\hline 2013-2018 & 31,702 & $10-13^{* *}$ & $24-30^{* *}$ & 0.20 & Present study \\
\hline
\end{tabular}

NA, data not available.

"Range of AFM, contamination detected in different types of milk (i.e. HQM, NQM, AQM, or OM) or in samples collected in different Italian regions.

includes results obtained based on 3-6,537 samples taken within 1 or 2 years. Our study is the first, which evaluates the monthly variation of $\mathrm{AFM}_{1}$ exposure, based on 300-650 samples per month totaling 31,702 samples during the period of almost 6 years (69 months), enabling the reliable estimation of the mean $\mathrm{AFM}_{1}$ concentrations, and the corresponding EDI values, and demonstrates their fluctuations over the years.

\section{CONCLUSIONS}

Although the results of this investigation showed a low risk of HCC for the adolescent and adult population attributable to intake of $\mathrm{AFM}_{1}$ via milk consumption during the study period (2013-2018), it should be considered that the present study does not include the $\mathrm{AFM}_{1}$ intake due to other milk-based products, e.g., cheese and yoghurt, which could add a notable amount to the estimated quantity consumed. Furthermore, it should be taken into account that our EDI calculations could not include the exposure derived from the consumption of mother's milk either, because we had no data on the combined intake of breast milk and cow milk. Breast milk may also contain $\mathrm{AFM}_{1}$ derived from cow milk as well as from the mother's food contaminated with $\mathrm{AFB}_{1}$ (Galvano et al., 2008; Radonić et al., 2017). In Italy, the $\mathrm{AFM}_{1}$ contamination was found in four (5\%) breast milk samples [ranging from $<7$ to $140 \mathrm{ng} \mathrm{L}{ }^{-1}$; mean $=55.35 \mathrm{ng} \mathrm{L}^{-1}$ (Galvano et al., 2008)]. Another Italian study revealed that $\mathrm{AFM}_{1}$ was detected in $37 \%$ of samples (mean $=12 \mathrm{ng} \mathrm{L}^{-1} \pm \mathrm{SD}=11 \mathrm{ng} \mathrm{ml}^{-1}$; range $\left.=3-340 \mathrm{ng} \mathrm{L}^{-1}\right)$ taken from patients $(n=30)$ with celiac disease, while in the healthy control group, the mean $\mathrm{AFM}_{1}$ concentration levels $\left(9 \pm 07 \mathrm{ng} \mathrm{L}^{-1}\right.$; range $\left.=3-67 \mathrm{ng} \mathrm{L}^{-1}\right)$ were lower (Valitutti et al., 2018). The latter results indicate that the exposure of infants can be substantially higher than our estimate depending on the dietary pattern of the mothers. Further investigation is needed to evaluate the total exposure for this contaminant for all population groups.

The previous Aflatoxin crisis due to high $\mathrm{AFB}_{1}$ contamination of maize has increased the awareness of the food safety risk managers; induced regulatory measures, research, and innovation activities; and reinforced the consciousness of the food business operators. Consequently, they have implemented strict monitoring and regular control along the feed and food chain utilizing the availability of rapid and less expensive detection kits. This self-control and corrective measures at dairy farms resulted in the slow decrease of $\mathrm{AFM}_{1}$ contamination.

Nevertheless, the variability of climatic conditions throughout years and the number of other factors that may influence $\mathrm{AFB}_{1}$ contamination of crops and consequently $\mathrm{AFM}_{1}$ contamination of milk underline the need of continuous monitoring of milk contamination and regular update of the exposure assessments.

\section{DATA AVAILABILITY STATEMENT}

The datasets generated for this study will not be made publicly available. The dataset is based on confidential private industry data.

\section{AUTHOR CONTRIBUTIONS}

ÁA, AS, and FG contributed to the conception and design of the study. AC and $\mathrm{AZ}$ organized the database. $\mathrm{PB}$ and $\mathrm{KK}$ performed the statistical analysis. AS wrote the first draft of the manuscript. KK, ZF, and ÁA finalized the manuscript and prepared for publication. All authors contributed to manuscript revision, read and approved the submitted version.

\section{FUNDING}

Project no. 2018-1.2.1-NKP-2018-00002 (to KK, ZF, and ÁA) has been implemented with the support provided from the National Research, Development and Innovation Fund of Hungary, financed under the 2018-1.2.1-NKP funding scheme.

\section{ACKNOWLEDGMENTS}

The current study contributes to the Ph.D. research of KK being carried out in the Food Science Doctoral School, Faculty of Food Sciences, Szent Istvan University, Hungary. 


\section{REFERENCES}

Anfossi, L., Baggiani, C., Giovannoli, C., D’Arco, G., Passini, C., and Giraudi, G. (2011). Occurrence of aflatoxin $\mathrm{M}_{1}$ in Italian cheese: results of a survey conducted in 2010 and correlation with manufacturing, production season, milking animals, and maturation of cheese. Food Control 25, 125-130. doi: 10.1016/j.foodcont.2011.10.027

Bellio, A., Bianchi, D. M., Gramaglia, M., Loria, A., Nucera, D., Gallina, S., et al. (2016). Aflatoxin $M_{1}$ in cow's milk: method validation for milk sampled in Northern Italy. Toxins 8, 57. doi: 10.3390/toxins8030057

Bogalho, F., Duarte, S., Cardoso, M., Almeida, A., Cabeças, R., Lino, C., et al. (2018). Exposure assessment of Portuguese infants to aflatoxin M1 in breast milk and maternal social-demographical and food consumption determinants. Food Control 90, 140-145. doi: 10.1016/j.foodcont.2018.02.043

Boudra, H., Barnouin, J., Dragacci, S., and Morgavi, D. P. (2007). Aflatoxin M1 and ochratoxin A in raw bulk milk from French dairy herds. J. Dairy Sci. 90, 3197-3201. doi: 10.3168/jds.2006-565

Campagnollo, F. B., Ganev, K. C., Khaneghah, A. M., Portela, J. B., Cruz, A. G., Granato, D., et al. (2016). The occurrence and effect of unit operations for dairy products processing on the fate of aflatoxin M1: a review. Food Control 68, 310-329. doi: 10.1016/j.foodcont.2016.04.007

Canever, A., Serraino, A., and Rosmini, R. (2004). "Presenza di aflatossine nei mangimi desti- nati all'alimentazione animale" in Proceedings of the 14th National Congress of AIVI, Santuario di Vicoforte (CN), Italy. ed. Associazione Italiana Veterinari Igienisti (AIVI) (Italy: Associazione Italiana Veterinari Igienisti (AIVI), Ozzano dell'Emilia (Bologna)), 451-455.

Cano-Sancho, G., Sanchis, V., Marín, S., and Ramos, A. J. (2013). Occurrence and exposure assessment of aflatoxins in Catalonia (Spain). Food Chem. Toxicol. 51, 188-193. doi: 10.1016/j.fct.2012.09.032

Cullen, J. M., Reubner, B. H., Hsieh, L. S., Hyde, D. M., and Hsieh, D. P. (1987). Carcinogenicity of dietary Aflatoxin M1 in male fisher rats compared to aflatoxin B1. Cancer Res. 47, 1913-1917.

Duarte, S. C., Almeida, A. M., Teixeria, A. S., Pereira, A. L., Falcão, A. C., Pena, A., et al. (2013). Aflatoxin M1 in marketed milk in Portugal: assessment of human and animal exposure. Food Control 30, 411-417. doi: 10.1016/j. foodcont.2012.08.002

EFSA (2004). Opinion of the scientific panel on contaminants in the food chain on a request from the commission related to Aflatoxin B1 as undesirable substance in animal feed. EFSA J. 39, 1-27. doi: 10.2903/j.efsa.2004.39

EFSA Scientific Committee (2007). Opinion of the scientific panel on contaminants in the food chain on a request from the commission related to the potential increase of consumer health risk by a possible increase of the existing maximum levels for aflatoxins in almonds, hazelnuts and pistachios and derived products. EFSA J. 446, 1-127. doi: 10.2903/j. efsa.2007.446

EFSA Scientific Committee (2012). Scientific opinion on the applicability of the margin of exposure approach for the safety assessment of impurities, which are both genotoxic and carcinogenic in substances added to food/ feed. EFSA J. 10:2578. doi: 10.2903/j.efsa.2012.2578

European Community (2006). Commission Regulation (EC) No 1881/2006 of 19 December 2006 setting maximum levels for certain contaminants in foodstuffs. Offic. J. Eur. Union L364/5.

Fakhri, Y., Ghorbani, R., Taghavi, M., Keramati, H., Amanidaz, N., Moradi, B., et al. (2019b). Concentration and prevalence of Aflatoxin M-1 in human breast Milk in Iran: systematic review, meta-analysis, and carcinogenic risk assessment: a review. J. Food. Protect. 82, 785-795. doi: 10.4315/0362-028X. JFP-18-367

Fakhri, Y., Rahmani, J., Oliveira, C. A. F., Franco, L. T., Corassin, C. H., Saba, S., et al. (2019a). Aflatoxin M1 in human breast milk: a global systematic review, metaanalysis, and risk assessment study (Monte Carlo simulation). Trends Food Sci. Tech. 88, 333-342. doi: 10.1016/j.tifs.2019.03.013

FAO/WHO Codex Alimentarius (2014). Code of practice for the prevention and reduction of mycotoxin contamination in cereals (CAC/RCP 51-2003). Adopted 2003. Revised 2014.

FAO/WHO Codex Alimentarius (1995). General Standard for Contaminants and Toxins in Food and Feed. Adopted in 1995. (CXS 193-1995) Revised in $1997,2006,2008,2009$. Amended in 2010, 2012, 2013, 2014, 2015, 2016, 2017, 2018, 2019.
Flores-Flores, M. E., Lizarraga, E., Lopez de Cerain, A., and Gonza lez-Penas, E. (2015). Presence of mycotoxins in animal milk: a review. Food Control 53, 163-176. doi: 10.1016/j.foodcont.2015.01.020

Frazzoli, C., Gherardi, P., Saxena, N., Belluzzi, G., and Mantovani, A. (2017). The hotspot for (global) one health in primary food production: Aflatoxin M1 in dairy products. Front. Public Health 4:294. doi: 10.3389/fpubh.2016.00294

Gallo, A., and Masoero, F. (2010). In vitro models to evaluate the capacity of different sequestering agents to adsorb aflatoxins. Ital. J. Anim. Sci. 9:e21. doi: 10.4081/ijas.2010.e21

Galvano, F., Pietri, A., Bertuzzi, T., Gagliardi, L., Ciotti, S., Luisi, S., et al. (2008). Maternal dietary habits and mycotoxin occurrence in human mature milk. Mol. Nutr. Food Res. 52, 496-501. doi: 10.1002/mnfr.200700266

Giorni, P., Magan, N., Pietri, A., Bertuzzi, T., and Battilani, P. (2007). Studies on Aspergillus flavi isolated from maize in northern Italy. Int. J. Food Microbiol. 113, 330-338. doi: 10.1016/j.ijfoodmicro.2006.09.007

Gonzales-Osnaya, L., Soriano, J. M., Moltò, J. C., and Manez, J. (2008). Simple liquid chromatography assay for analyzing ochratoxin in bovine milk. Food Chem. 108, 272-276. doi: 10.1016/j.foodchem.2007.10.013

Hsieh, D. P., Cullen, J. M., and Ruebner, B. H. (1984). Comparative hepatocarcinogenicity of aflatoxins B1 and M1 in the rat. Food Chem. Toxicol. 22, 1027-1028. doi: 10.1016/0278-6915(84)90160-1

Joint FAO/WHO Expert Committee on Food Additives (2001). Safety evaluation of certain mycotoxins in food. Available at: http://www.inchem.org/documents/ jecfa/jecmono/v47je01.htm (Accessed September 10, 2018).

Kebede, H., Abbas, H. K., Fisher, D. K., and Bellaloui, N. (2012). Relation between aflatoxin contamination and physiological response of corn plants under drought and heat stress. Toxins 4, 1385-1403. doi: 10.3390/toxins4111385

Kerekes, K., Bonilauri, P., Serraino, A., Giacometti, F., Piva, S., Zambrini, V., et al. (2016). An effective self-control strategy for the reduction of aflatoxin M1 content in milk and to decrease the exposure of consumers. Food Addit. Contam. A 33, 1840-1849. doi: 10.1080/19440049.2016.1241895

Kuiper-Goodman, T. (1990). Uncertainties in the risk assessment of three mycotoxins: aflatoxin, ochratoxin, and zearalenone. Can. J. Physiol. Pharmacol. 68, 1017-1024. doi: 10.1139/y90-155

Kunter, I., Hürer, N., Gülcan, H. O., Öztürk, B., Dogan, I., and Sahin, G. (2017). Assessment of Aflatoxin M1 and heavy metal levels in mothers breast milk in Famagusta. Cyprus. Biol. Trace Elem. Res. 175, 42-49. doi: 10.1007/ s12011-016-0750-z

Leblanc, J. C., Tard, A., Volatier, J. L., and Verger, P. (2005). Estimated dietary exposure to principal food mycotoxins from the first French Total Diet Study. Food Addit. Contam. 22, 652-672. doi: 10.1080/02652030500159938

Leclercq, C., Arcella, D., Piccinelli, R., Sette, S., Le Donne, C., and Turrini, A. (2009). The Italian National Food Consumption Survey INRAN-SCAI 2005-06: main results in terms of food consumption. Public Health Nutr. 12, 2504-2532. doi: $10.1017 /$ S1368980009005035

Madali, B., Gulec, A., and Ayaz, A. (2018). A survey of Aflatoxin M1 in different milk types in Turkey: risk assessment of children's exposure. Prog. Nutr. 20, 659-664. doi: 10.23751/pn.v20i4.6889

Marchetti, G., Serraino, A., Giacometti, F., Bonfante, E., and Rosmini, R. (2013). Rassegna sulle aflatossine negli alimenti e nei mangimi: fonti di contaminazione per l'uomo e controllo. Ind. Aliment 52, 7-19. Avilable at: https://www. chiriottieditori.it/it/industrie-alimentari/883

Martins, H. M., Guerra, M. M., and Bernardo, F. (2005). A six year survey (1999-2004) of the occurrence of aflatoxin M1 in daily products produced in Portugal. Mycotoxin Res. 21, 192-195. doi: 10.1007/BF02959261

Mauro, A., Battilani, P., and Cotty, P. J. (2014). Atoxigenic Aspergillus flavus endemic to Italy for biocontrol of aflatoxins in maize. BioControl 60, 125-134 doi: 10.1007/s10526-014-9624-5

Mauro, A., Garcia-Cela, E., Pietri, A., Cotty, P. J., and Battilani, P. (2018). Biological control products for Aflatoxin prevention in Italy: commercial field evaluation of Atoxigenic Aspergillus flavus active ingredients. Toxins 10:30. doi: 10.3390/toxins 10010030

Miliĉeviĉ, D., Petronijeviĉ, R., Petroviĉ, Z., Đjinoviĉ-Stojanoviĉ, J., Jovanoviĉ, J., Baltiĉ, T., et al. (2019). Impact of climate change on aflatoxin M1 contamination of raw milk with special focus on climate conditions in Serbia. J. Sci. Food Agric. 99, 5202-5210. doi: 10.1002/jsfa.9768

Milićević, D. R., Spirić, D., Radičević, T., Velebit, B., Stefanović, S., Milojević, L., et al. (2017). A review of the current situation of aflatoxin M1 in cow's 
milk in Serbia: risk assessment and regulatory aspects. Food Addit. Contam. Part A. 34, 1617-1631. doi: 10.1080/19440049.2017.1363414

Ministero della Salute. Nota del Ministero della Salute prot. n. 855 del 16/1/2013Aflatossine (2013). Extraordinary operating procedures for the prevention and management of the risk of aflatoxin contamination in the dairy supply chain and in the production of maize destined for human and animal nutrition, following extreme weather conditions. Available at: http://www.unionalimentari. com/website/law.aspx?id=1287\&key=\&fl= (Accessed December 2018).

NIST/SEMATECH (2013). E-Handbook of statistical methods. Available at: http://www.itl.nist.gov/div898/handbook (Accessed August 2018).

Oluwafemi, F., Badmos, A. O., Kareem, S. O., Ademuyiwa, O., and Kolapo, A. L. (2014). Survey of aflatoxin M1 in cows' milk from free-grazing cows in Abeokuta, Nigeria. Mycotoxin Res. 30, 207-211. doi: 10.1007/s12550-014-0204-4

Pardakhti, A., and Maleki, S. (2019). Risk assessment of Aflatoxin M1 contamination of milk in Iran. Int. J. Environ. Res. 13, 265-271. doi: 10.1007/ s41742-019-00172-1

Perrone, G., Gallo, A., and Logrieco, A. F. (2014). Biodiversity of Aspergillus section Flavi in Europe in relation to the management of aflatoxin risk. Front. Microbiol. 5:377. doi: 10.3389/fmicb.2014.00377

Prandini, A., Tansini, G., Sigolo, S., Filippi, L., Laporta, M., and Piva, G. (2009). On the occurrence of aflatoxin M1 in milk and dairy products. Food Chem. Toxicol. 47, 984-991. doi: 10.1016/j.fct.2007.10.005

Radonić, J. R., Kocić Tanackov, S. D., Mihajlović, I. J., Grujić, Z. S., Vojinović Miloradov, M. B., Škrinjar, M. M., et al. (2017). Occurrence of aflatoxin M1 in human milk samples in Vojvodina, Serbia: estimation of average daily intake by babies. J. Environ. Sci. Heal. Part B 52, 59-63. doi: 10.1080/03601234.2016.1229454

Rahmani, J., Alipour, S., Miri, A., Fakhri, Y., Riahi, S. M., Keramati, H., et al. (2018). The prevalence of aflatoxin M1 in milk of Middle East region: a systematic review, meta-analysis and probabilistic health risk assessment. Food Chem. Toxicol. 118, 653-666. doi: 10.1016/j.fct.2018.06.016

Rama, A., Latifi, F., Bajraktari, D., and Ramadani, N. (2015). Assessment of aflatoxin M1 levels in pasteurized and UHT milk consumed in Prishtina, Kosovo. Food Control 57, 351-354. doi: 10.1016/j.foodcont.2015.04.021

Rodríguez-Velasco, M. L., Calonge Delso, M. M., and Ordónez Escudero, D. (2003). ELISA and HPLC determination of the occurrence of aflatoxin M(1) in raw cow's milk. Food Addit. Contam. 20, 276-280. doi: 10.1080/ 0265203021000045208

Rosi, P., Borsari, A., Lasi, G., Lodi, S., Galanti, A., Fava, A., et al. (2007). Aflatoxin M1 in milk: reliability of the immunoenzymatic assay. Int. Dairy J. 17, 429-435. doi: 10.1016/j.idairyj.2006.05.003

Roussi, V., Govaris, A., Varagouli, A., and Botsoglou, N. A. (2002). Occurrence of aflatoxin $\mathrm{M}(1)$ in raw and market milk commercialized in Greece. Food Addit. Contam. 19, 863-868. doi: 10.1080/02652030210146864

Scaglioni, P. T., Becker-Algeri, T., Drunkler, D., and Badiale-Furlong, E. (2014). Aflatoxin B1 and M1 in milk. Anal. Chim. Acta 829, 68-74. doi: 10.1016/j. aca.2014.04.036
Serraino, A., Trevisani, M., Boscolo, D., and Rosmini, R. (2003). AFM1 pollution in Italian raw milk: quantitative risk assessment for consumer. Ind. AlimentItal. 42, 1113-1119. doi: 10.4315/0362-028X.JFP-12-163

Shundo, L., Navas, S. A., Conceiçăo, L., Lamardo, A., Ruvieri, V., and Sabino, M. (2009). Estimate of aflatoxin M1 exposure in milk and occurrence in Brazil. Food Control 20, 655-657. doi: 10.1016/j.foodcont.2008.09.019

Temamogullari, F., and Kanici, A. (2014). Short communication: Aflatoxin M1 in dairy products sold in Şanlıurfa, Turkey. J. Dairy Sci. 97, 162-165. doi: 10.3168/jds.2012-6184

Trevisani, M., Farkas, Z., Serraino, A., Zambrini, V. A., Pizzomiglio, V., Giacometti, F, et al. (2014). Analysis of industry generated data part I. a baseline for the development of a tool to assist milk industry in the design of sampling plans for controlling aflatoxin $\mathrm{M}_{1}$ in milk. Food Addit. Contam. A 31, 1246-1256. doi: 10.1080/19440049.2014.925587

Trevisani, M., Serraino, A., Canever, A., Varisco, G., and Boni, P. (2006). "Quantitative risk assessment of aflatoxicosis associated with milk consumption in Italy (2000-2004)" in Towards a risk-based chain control. eds. F. J. M. Smulders, and J. D. Collins (The Netherlands: Wageningen Academic Publisher), 91-114.

Tsakiris, I. N., Tzatzarakis, M. N., Athanasios, K., Alegakis, A. K., Vlachou, M. I., Renieri, E. A., et al. (2013). Risk assessment scenarios of children's exposure to aflatoxin M1 residues in different milk types from the Greek market. Food Chem. Toxicol. 56, 261-265. doi: 10.1016/j.fct.2013.02.024

Udovicki, B., Djekic, I., Eleni, P., Kalogianni, E. P., and Rajkovic, A. (2019). Exposure assessment and risk characterization of Aflatoxin M1 intake through consumption of milk and yoghurt by student population in Serbia and Greece. Toxins 11, 205-216. doi: 10.3390/toxins11040205

Valitutti, F., De Santis, B., Trovato, C. M., Montuori, M., Gatti, S., Oliva, S., et al. (2018). Assessment of mycotoxin exposure in breastfeeding mothers with celiac disease. Nutrients. 10:336. doi: 10.3390/nu10030336

WHO (1997). Evaluation of certain food additives and contaminants, Fourtyninth report of the Joint FAO/WHO Expert Committee on Food Additives, WHO Technical Report Series, 884, 69-77.

Conflict of Interest: AC and AZ were employed by company Granarolo S.p.A., Bologna, Italy.

The remaining authors declare that the research was conducted in the absence of any commercial or financial relationships that could be construed as a potential conflict of interest.

Copyright (๑) 2019 Serraino, Bonilauri, Kerekes, Farkas, Giacometti, Canever, Zambrini and Ambrus. This is an open-access article distributed under the terms of the Creative Commons Attribution License (CC BY). The use, distribution or reproduction in other forums is permitted, provided the original author(s) and the copyright owner(s) are credited and that the original publication in this journal is cited, in accordance with accepted academic practice. No use, distribution or reproduction is permitted which does not comply with these terms. 